\title{
Through-Life Hybrid Fatigue Assessment of Naval Ships
}

\section{Teresa Magoga}

Maritime Division, Defence Science and Technology Group, Melbourne, Australia

Australian Maritime College, University of Tasmania, Launceston, Australia

Seref Aksu

Maritime Division, Defence Science and Technology Group, Melbourne, Australia

\section{Stuart Cannon}

Maritime Division, Defence Science and Technology Group, Melbourne, Australia

\section{Roberto Ojeda}

Australian Maritime College, University of Tasmania, Launceston, Australia

\section{Giles Thomas}

Faculty of Engineering Sciences, University College London, London, United Kingdom

Teresa Magoga, Maritime Division, Defence Science and Technology Group, 506 Lorimer Street, Fishermans Bend 3207, Australia, Teresa.Magoga@dst.defence.gov.au 


\section{Glossary}

$3 \mathrm{D}$

Three-dimensional

AS

Aircraft Structural Integrity

CDT Cumulative Damage Theory

D Fatigue damage

DNV Det Norske Veritas

E Modulus of Elasticity

[GPa]

FEA Finite Element Analysis

$\mathrm{FL}_{\mathrm{d}} \quad$ Design life $\quad$ [years]

$\mathrm{FL}_{\mathrm{m}} \quad$ Time from commissioning to discovery of first crack [years]

$\mathrm{FL}_{\mathrm{p}} \quad$ Predicted fatigue life [years]

HMAS Her Majesty's Australian Ship

HMS Hull Monitoring System

HSLC High Speed Light Craft

i Sample

K Stress range ratio

m Inverse slope of S-N curve

$\mathrm{m}_{1} \quad$ First $\mathrm{S}-\mathrm{N}$ inverse slope gradient

$\mathrm{m}_{2} \quad$ Second $\mathrm{S}-\mathrm{N}$ inverse slope gradient

MRU Motion Reference Unit

n Number of stress cycles

$\mathrm{N} \quad$ Number of stress cycles to failure

RAN Royal Australian Navy

S-N Fatigue resistance of a material

$\overline{\mathrm{a}} \quad \mathrm{S}-\mathrm{N}$ curve parameter 
v

$\Delta \sigma$

$\Delta \sigma_{\max }$

$\sigma_{\text {yield }}$
Poisson's ratio

Stress range

[MPa]

Maximum stress cycle

[MPa]

Yield strength
[MPa] 


\section{Through-Life Hybrid Fatigue Assessment of Naval Ships}

When a ship enters service it has an implied or calculated design fatigue life. Factors including construction quality, loads, material performance, and operational profile are assumed. However, these factors vary through life. Failure of structural items due to fatigue cracking can lead to increased cost of ownership and reduced capability. Therefore, to allow informed decision-making regarding fleet availability and economy, it is necessary to monitor the variables that influence a ship's fatigue life. This paper presents a new method whereby in-service data, fleet maintenance reports, and Finite Element Analysis are incorporated to predict ongoing fatigue life and hence support the management of the remaining service life of a ship. The method is applied to a naval High Speed Light Craft to demonstrate its merit. The fatigue lives of different welded details are predicted using a practical implementation of the S-N curve approach, employed with strain and operational data acquired from an on-board hull monitoring system. The proposed method is efficient because it is properly linked to stress analysis, inherently includes the influence of the operational profile, and is a balance between accuracy and effort.

Keywords: fatigue life analysis, hull monitoring system, maintenance data, naval ships, Eurocode 9

\section{Introduction}

The service life of a ship can be dictated by its structural fatigue life. Fatigue is defined as the weakening of a structural part through crack initiation and propagation, caused by repeated stress fluctuations under cyclic loads.

Fatigue analysis is generally conducted using fracture mechanics or the S-N curve approach. Fracture mechanics concerns modelling of the growth of cracks after initiation, based on an empirical relationship between the stress intensity factor range and the crack growth. The main input parameters are the crack dimensions, the material crack growth data, and the applied stress ranges or spectrum. The S-N curve approach, based on empirical data collected from fatigue tests of common structural details, is combined with cumulative damage theory (Miner 1945). The S-N curve approach is currently the preferred approach in 
the design of ship structures (Collette and Incecik 2006, Doshi and Vhanmane 2013, Soliman, Barone and Frangopol 2015).

In the design of ship structures, factors such as construction quality, operational loads, material performance, and maintenance quality are assumed. These factors change over the life of a ship, which in turn affect the accuracy of the structural service life estimated during design (Ibrahim 2015). An additional source of variability for many naval ships is the operational profile (Phelps and Morris 2013). Safety factors and margins are typically used to account for differences between the actual operational conditions and those assumed during design. However, the application of margins in ship design may not be a suitable means to allow for changing operational requirements through-life (Koenig, Nalchajian and Hootman 2009, Magoga and Dwyer 2018). Further, with the exception of the hull girder capacity and material allowances, it is difficult to identify the safety factors in classification society rules because they are often implicit within empirical equations.

In military aviation, Aircraft Structural Integrity (ASI) management has been a core part of platform and operational safety for several decades (Molent and Aktepe 2000). ASI management is the basis for fleet availability and realisation of the design life without major unforeseen remediation (Directorate General Technical Airworthiness 2014, Military Aviation Authority 2015). Both the safe-life and damage tolerance philosophies are accepted. Effective fatigue management includes, but is not limited to, the measurement of in-service loads and environmental conditions, cataloguing information on the structural configuration and maintenance, and regular operator feedback (Molent and Aktepe 2000).

In the maritime industry, lifecycle assessment and management is less prolific. It is generally recognised that integrated approaches, which take into account uncertainty, can better inform decision-makers about a ship's structural health. However, for widespread adoption of technology and methods that support through-life structural integrity 
management a change in culture is needed (Hess, Aksu, Blake, Boote, Caridis, Egorov, Fjeldstad, Hoogeland, Murayama, Anderson and Tammer 2015).

Interest in the measurement and utilisation of the structural responses and operational parameters of naval ships has recently grown. The drivers of this trend include:

- The increase in vessel size, which has intensified the importance of global loads and dynamic responses (Ferraris and Farinetti 2008, Soliman, et al. 2015, Swartz, Zimmerman, Lynch, Rosario, Brady, Salvino and Law 2012).

- The use of weight-optimised structures, which typically feature inserts and cut-outs (Ferraris and Farinetti 2008, Huang, Harbison, Kvidahl, Niolet, Walks, Christein, Smitherman, Phillippi, Dong, De Can, Caccese, Blomquist, Kihl, Wong, Sinfield, Nappi, Gardner, Wong, Bjornson and Manuel 2016).

- The use of marine-grade aluminium. Whilst both steel and aluminium alloys are susceptible to fatigue, the latter generally has a lower capacity to withstand cyclic loads. This is due to the loss of strength in the heat-affected zone during welding, greater sensitivity to flaws, a relatively fast crack propagation rate under fatigue loading, and difficulties with fabrication (Ferraris and Farinetti 2008, Sielski 2008).

Stambaugh et al. (2014) described a project to assess fatigue design approaches for the United States Coast Guard Cutters. Essential to this study was the measurement of the wave environment and strain responses during a monitoring campaign. This enabled sufficient quantification of the uncertainties in spectral fatigue analysis, leading to timevarying sustainment evaluations. Okasha et al. (2011) demonstrated an approach to analyse data obtained from a structural health monitoring system, installed on-board a naval aluminium wave-piercing catamaran, for reliability analysis and damage detection. Similar work is also gaining traction in commercial shipping applications. For example, field 
measurements of local ice loads were carried out on-board an icebreaking research vessel. Subsequently, the analysis of fatigue damage on the side-shell of the vessel's bow thruster room was performed (Hwang, Lee, Kang and Suh 2016).

The operational costs arising from maintenance activities can be significant in assetintensive industries (Hodkiewicz and Tien-Wei Ho 2016). For naval ships, an unplanned failure of a critical component can manifest as increased cost of ownership, reduced operational availability, or a condition of class enforced by the regulatory body. At the same time, fiscal and/or political constraints are placing smaller navies under pressure to extend the longevity of their ships (Hess, et al. 2015, Temple and Collette 2015). Whilst full-scale fatigue prototypes and destructive testing of platforms removed from service is common in military aviation, it is impractical for ships due to the scale and associated costs (Zhu and Collette 2011). Accordingly, data collection and fatigue analysis of ship structures should be efficient. However, research has tended to be focused on increasing the modelling accuracy and fidelity. The approaches also tend to be validated via other numerical methods and experimental data (Chakarov, Garbatov and Guedes Soares 2008, Matic and Domazet 2005, Meneghetti 2008, Shen, Yan, Barltrop, Liu and Song 2016, Thévenet, Ghanameh and Zeghloul 2013, Xiao and Yamada 2004). In comparison, use of in-service load and response data combined with survey reports to update service life predictions has been limited. Although a number of techniques have been developed, little work has been completed on compiling the information from analyses and inspections (Hifi and Barltrop 2015).

Therefore, the aim of this work is to propose a new through-life hybrid fatigue assessment method. This method combines measured full-scale data, survey reports, and numerical tools in a practical manner. The method is applied to a naval High Speed Light Craft (HSLC) to demonstrate its merit. 


\section{Proposed Through-Life Hybrid Fatigue Assessment Method}

The key steps of the proposed through-life hybrid fatigue assessment method are depicted in Figure 1.

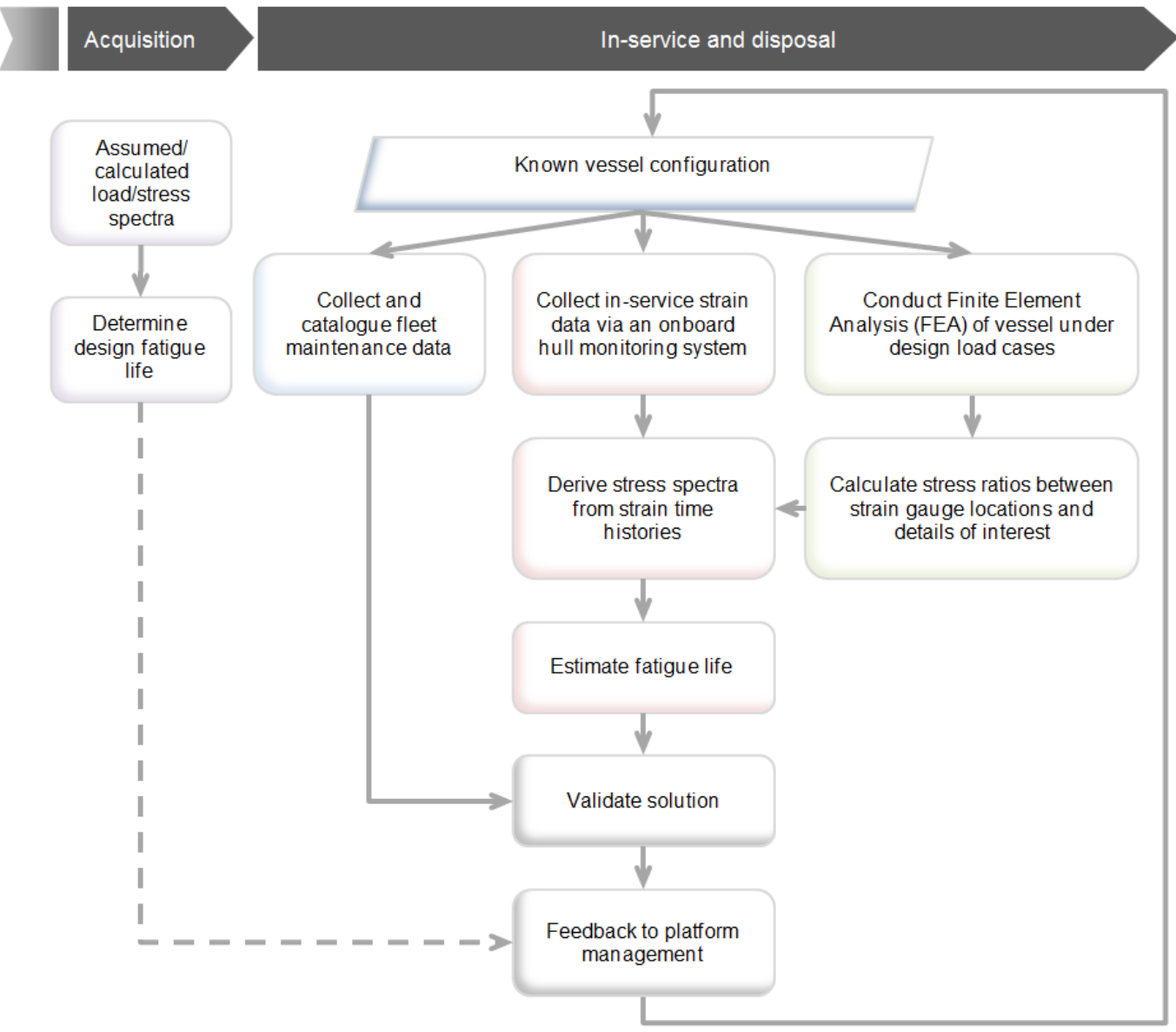

Figure 1. Process to estimate and update fatigue life

The design fatigue life of a ship can be implied or estimated from classification society rules, or a direct fatigue analysis. The design life assumptions include the construction quality, loads, material performance, operational area, and operational profile. However, the 'as-built' configuration of the vessel and the actual operational profile are very likely to differ from those specified. In the proposed method, in-service data, fleet maintenance reports, and Finite Element Analysis (FEA) are incorporated to predict the 
remaining service life of a ship. Via an on-board hull monitoring system, data including the structural responses (strains), speed profile, and area of operations is collected. The S-N curve approach can then be applied to stress distributions or spectra derived from the strain data to perform direct fatigue analysis of critical details.

It is necessary to calibrate models that predict structural defects using expert judgement and in-service information, as this information leads to changes of the variables incorporated into the prediction (Hifi and Barltrop 2015). That is, real-world experience is utilised for continuous validation of the predictive model. Ships provide a number of innate indicators of degradation, such as cracks, that can be taken as a record of the structural condition (Groden and Collette 2017). Therefore, the validity of the updated (predicted) fatigue life is established via comparison to hull survey reports.

Feedback can then be provided to the operator. Variations in the usage of different ships, and between the usage assumed during design and the actual operational profile, can be highlighted. This information provides a sound basis for maintenance practices and throughlife cost savings, by avoiding unnecessary inspections of low risk areas and earlier detection of defects in high risk areas (Phelps and Morris 2013).

The predicted service life is periodically updated as the structural configuration and vessel's operations change, and with targeted monitoring and inspection. Also, with increasing data there is an opportunity to improve the fidelity of the modelling.

Although long-term strain monitoring is arguably the best way to determine the longterm stress distribution of the ship structure, in its absence a spectral (direct) procedure can be utilised. This procedure uses a seakeeping tool to calculate wave loads, necessary for stress analysis, for all regular waves of unit amplitude over a range of wave periods and ship headings. Thus, if information on the ship speed and encountered wave environment are 
obtained, these parameters can be input into the spectral approach within the proposed through-life hybrid fatigue assessment method.

\section{Cumulative Damage Theory coupled with S-N Curve Method Approach}

In this paper, Cumulative Damage Theory (CDT) coupled with the S-N curve method is used to estimate the fatigue life of the aluminium welded joints. CDT, also known as the Palmgren-Miner rule (Miner 1945), calculates the fatigue damage from each interval of the applied stress range as the ratio of the number of cycles (n) to the number of cycles $(\mathrm{N})$ to failure. $\mathrm{N}$ is determined from an $\mathrm{S}-\mathrm{N}$ curve. Though CDT coupled with the S-N curve method is widely accepted in the maritime industry (Du, Li, Zhang and Wang 2015, Hodapp, Collette and Troesch 2013, Maddox 2003, Yeter, Garbatov and Guedes Soares 2016) and in fatigue design codes (Hobbacher 2008, Technical Committee CEN/TC 250 1999), there are differing views regarding its accuracy.

CDT assumes that:

- The fatigue strength is dependent only on the stress range, and the effect of mean stress can be ignored.

- There is no interaction between the applied stress cycles. That is, the cycles can be linearly summed.

The latter assumption is an important difference to crack growth modelling. Zhang and Maddox (2009) suggest that the most significant effect on the fatigue behaviour is the stress cycle interaction, and that long and/or multiple crack paths that develop can significantly vary the fatigue life of full-scale structures. Hodapp, et al. (2013) and Cui, Wang and Huang (2011) criticise the sizeable uncertainty/error in the fatigue life values of a simple ship detail, evaluated via different industry approaches that employ CDT, due partly to the effects of the load sequence and initial flaw size being ignored. In addition, Ravi Chandran, Chang and Cashman (2010) argue that the traditional single S-N curve oversimplifies the 
diverse fatigue failure behaviour of metals. The authors' showed that the difference in fatigue lives between the types of crack initiation can be one or more orders of magnitude.

In comparison, Cosso, Rizzo and Servetto (2016) assessed the fitness-for-service of welded joints, representative of those found in ship and bridge structures, using scale-model experiments. The authors showed that the examined butt and cruciform joints behaved in accordance with the relevant detail design categories based on good fabrication. Of particular relevance to the present study, in 2000 the Ship Structures Committee reported that CDT 'provides a reasonably accurate, cost-effective result that is consistent with the level of available information in the high-speed craft industry' (Kramer, Rampolla and Magnussen 2000, p. 28). 17+ years later, CDT is still seen as fit-for-purpose for calculating the consumed fatigue life of an aluminium high-speed craft (Johnson, Lynch and Collette 2018), and to calculate the fatigue life of a cutter based on measured strains (Drummen, Hageman and Stambaugh 2017).

In addition, Neuberg and Drimer (2017) used the S-N curve in the development of a direct calculation method to address the fatigue limit state of an aluminium planing boat, because it is effective, well established, and applied by the Eurocode; the detail categories in Eurocode 9 are characterised partly by the crack initiation site (Technical Committee CEN/TC 250 1999). Eurocode 9 also takes into account the effect of exposure to harsh conditions, whereas the theory of fracture mechanics does not account for corrosion. Ultimately, for practical purposes, a fatigue assessment approach must be chosen. In light of the known shortfalls of CDT the presented method treats the fatigue life as a dynamic value, rather than a static value assumed or calculated during the design stage of the ship lifecycle. The uncertainty associated with using CDT coupled with the S-N curve approach is to an extent countered by incorporating ship maintenance data into the analysis framework. However, this does not negate the option to use more sophisticated methods in future. 


\section{Application of Method}

The method described in the previous section is applied to a study platform, the Royal Australian Navy 56 m Armidale Class Patrol Boat shown in Figure 2. The principal particulars are given in Table 1.

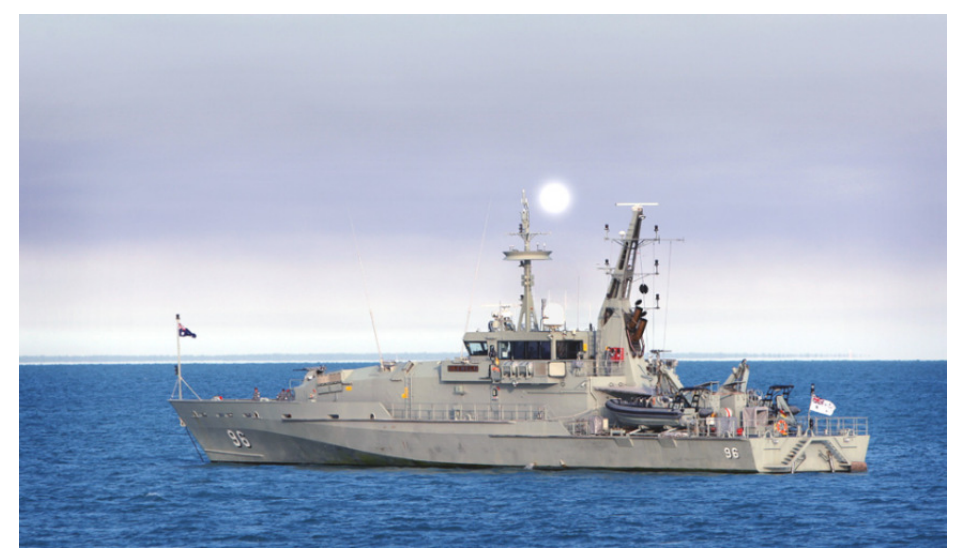

Figure 2. Armidale Class Patrol Boat HMAS Glenelg

Table 1. Armidale Class Patrol Boat principal particulars

\begin{tabular}{|l|l|}
\hline Length overall & $56.8 \mathrm{~m}$ \\
\hline Beam overall & $9.7 \mathrm{~m}$ \\
\hline Draught & $2.7 \mathrm{~m}$ \\
\hline Displacement (standard) & 300 tonne \\
\hline Top speed & $25 \mathrm{kn}$ \\
\hline
\end{tabular}

The patrol boats were designed by Austal Ships in Western Australia. Fourteen boats were built between 2004 and 2007. They feature a deep-vee, hard-chine, semi-planing hullform, and were constructed using marine-grade aluminium alloys. The boats were designed and are maintained to Det Norske Veritas (DNV) Rules for Classification of High Speed Light Craft (1996) supplemented by naval technical regulatory and safety rules as required. 
Thus, to ensure that the design life of 20 years would be met the allowable stress approach was followed, together with good detailed design and fabrication quality. An explicit fatigue analysis was not completed prior to the ships entering service.

Four welded details found on the patrol boat are considered in this paper:

(1) A pillar (hollow tube) joined to an end plate by a bevel-butt circumferential weld.

(2) A butt weld between a relatively thick insert and thinner deck plating.

(3) A built-up longitudinal beam comprised of web plating of different thickness joined by a butt weld and a flange joined by a continuous fillet weld.

(4) Longitudinal plating joined to transverse plating via a double fillet weld.

\section{Finite Element Analysis}

Stress analysis of the patrol boat is performed using FEA implemented in the commercial package MAESTRO (DRS Defense Solutions 2013).

The global model of the patrol boat represents the overall stiffness. To resolve stress concentrations at geometric discontinuities fine mesh substructures, with a density of half to one plate thickness, have been embedded into the global model. The local FEA models of the structural details are displayed in Table 2. 
Table 2. Analysed details of interest (positive $\mathrm{x}$-direction is forward, positive y-direction is up, and positive z-direction is to starboard)

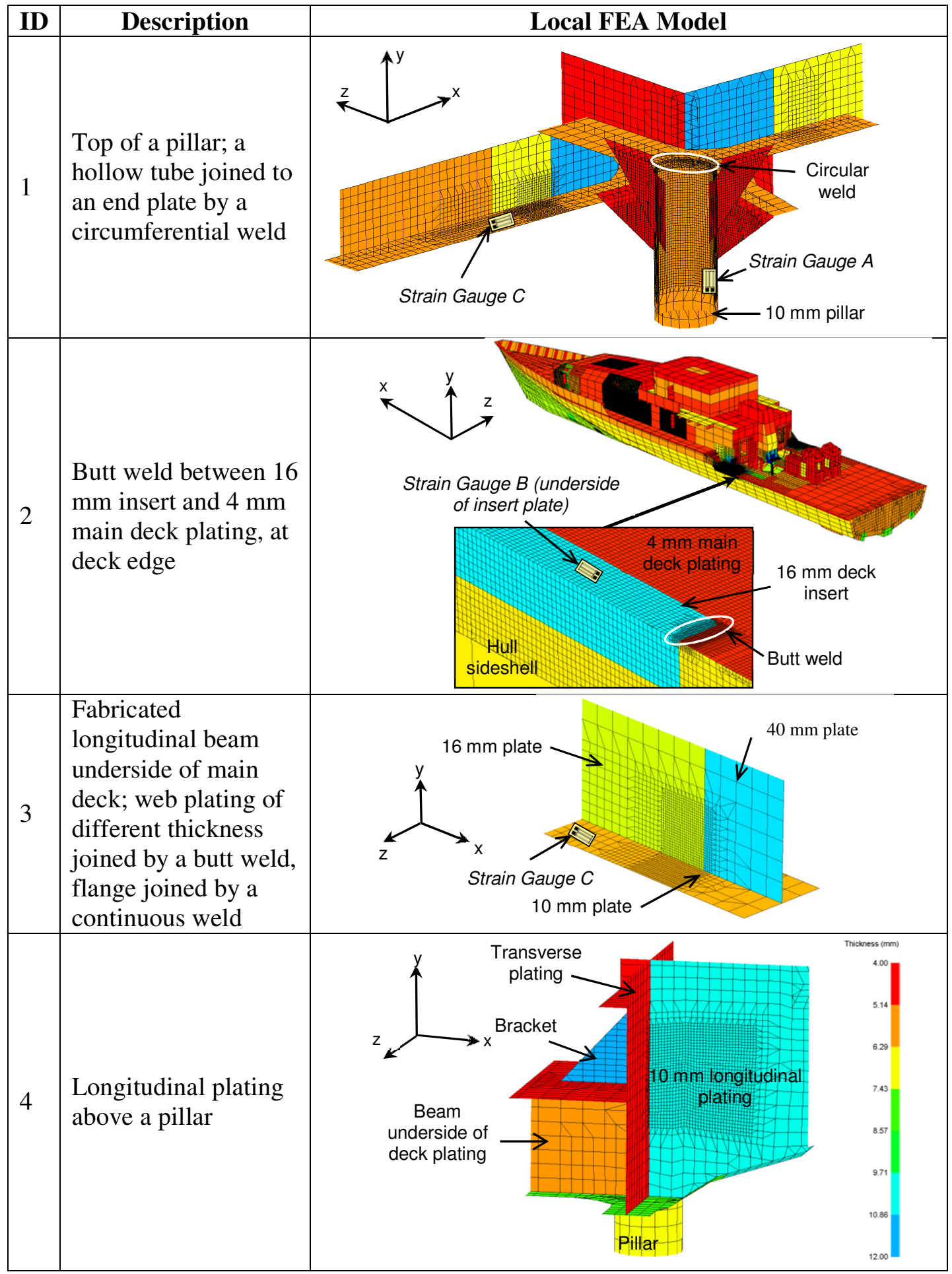


Two load cases are considered in the stress analysis, and are representative of the design loads calculated using DNV HSLC rules (2011):

- Hollow landing - the top of Sea State 6 in the sagging condition plus slam pressure applied to a forward section of the hull.

- Crest landing - the top of Sea State 6 in the hogging condition plus slam pressure applied to the mid-section of the hull.

\section{Fleet Maintenance Data}

Maintenance reports of cracking are used to validate the predicted fatigue life. The cracks occurring at the specified locations were fleet-wide occurrences rather than defects isolated to a single vessel. The presence or absence of a crack at a construction detail is interpreted as a sample of the corresponding fatigue life. This rationale is reflected in the International Association of Classification Societies description of 'damage experience', or the number, extent, location, and frequency of cracks related to the fleet, as the main source of information for maintenance planning (Common Structural Rules for Bulk Carriers and Oil Tankers 2010). Cracks are typically detected using visual inspection and dye penetrant inspection.

The maintenance records were reviewed to obtain the time from commissioning of a patrol boat to discovery of the first crack, $\mathrm{FL}_{\mathrm{m}}$ at various locations. Table 3 presents the average and standard deviation of $\mathrm{FL}_{\mathrm{m}}$ across the fleet for each detail of interest, normalised by that of ID-1. On average, cracking was first discovered at ID-2 followed by ID-1 and ID4. At the time of the analysis, no defects had been observed at ID-3. 
Table 3. Fleet average $\mathrm{FL}_{\mathrm{m}}$ at each detail of interest normalised by that of ID-1

\begin{tabular}{|l|l|l|}
\hline Detail & Fleet average $\mathrm{FL}_{\mathrm{m}}$ & Standard deviation of $\mathrm{FL}_{\mathrm{m}}$ \\
\hline ID-1 & 1.0 & $25 \%$ \\
\hline ID-2 & 0.72 & $31 \%$ \\
\hline ID-3 & N/A - no defects reported \\
\hline ID-4 & 1.2 & $9.3 \%$ \\
\hline
\end{tabular}

The standard deviation was greatest at ID-2 (31\%) followed by ID-1 (25\%) and ID-4 $(9.3 \%)$. This level of variation in the data is considered reasonable. Maintenance data often suffers from issues with accuracy, completeness, and timeliness (Hodkiewicz and Tien-Wei Ho 2016). Insulation must be removed to carry out inspection of parts of the internal structure. Thus, early detection of cracks occurring in insulated structures is more difficult than early detection of cracks occurring in the main deck. In addition, there can be a time gap between detection and reporting of a structural defect of up to six weeks, as has been highlighted discussed with the maintainer of the patrol boats.

\section{Collection of Full-Scale Data}

The Defence Science and Technology Group, Australia collaborated with Austal Ships to develop and commission a hull monitoring system (HMS) on-board the youngest vessel of the class HMAS Glenelg. The aims of the project were to develop a capability for structural longevity assessment, and to demonstrate the application of a versatile network using specialised sensors to collect performance data on a naval platform (Vincent, Gardiner, Wilson, Ellery and Armstrong 2008). Data was obtained from the HMS between May 2009 and February 2014.

The HMS was comprised of accelerometers, foil-based $45^{\circ}$ rosette and linear strain gauges, torsionmeters to measure shaft power, an inertial six-degree of freedom rigid body motion reference unit, and an external Global Positioning System receiver. The sensors were 
programmed to continuously collect and return data to a computer in the ship's office for storage.

The strain gauge locations considered in the present paper are shown in Figure 3, and indicated on the local FEA models of ID-1 and ID-2 in Table 2. The strain signals were sampled at $50 \mathrm{~Hz}$.

Figure 3. Analysed strain gauge locations shown on general arrangement (56.8m Armidale Class Patrol Boat Drawings 2003)

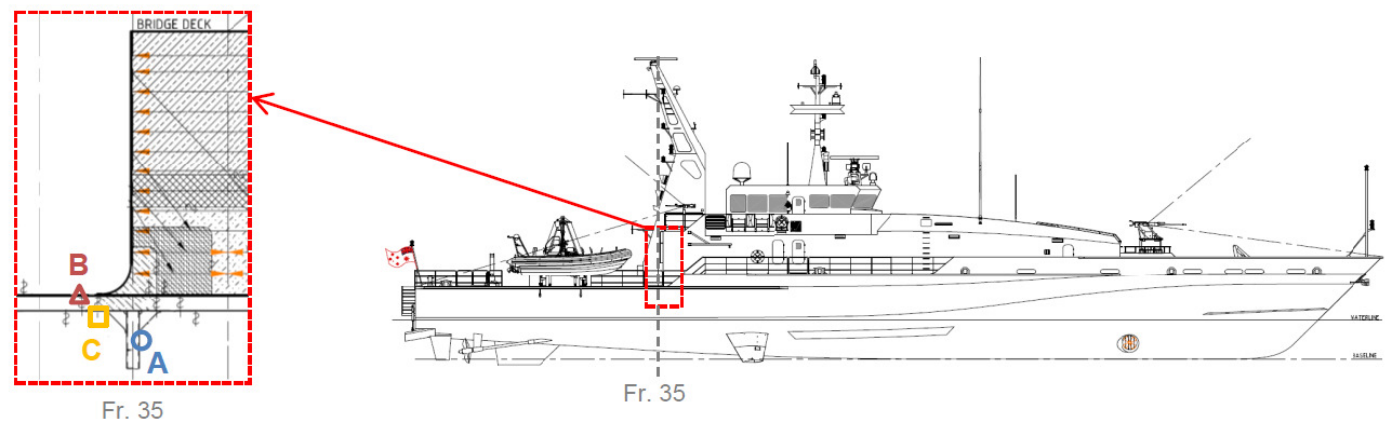

General Recommendations for Configuration of HMSs installed on Naval Ships

When planning installation of a HMS on-board a naval platform it is important that sensors are specified and located to meet the aims of the HMS. The following are general recommendations (Magoga, Aksu, Cannon, Ojeda and Thomas 2017, Phelps and Morris 2013):

- To use the global wave loading as a hull-girder fatigue indicator, install strain gauges along the length of the vessel. Further, these strain gauges should be located away from bending nodes to ensure that appreciable structural excitation is detected. This can be checked via natural frequency analysis (generally, the first and second modes are sufficient). 
- To understand localised fluctuating stresses that induce fatigue damage, install strain gauges in proximity to highly stressed or cracking-prone details. However, care should be taken to ensure that placement of strain gauges is not unduly influenced by stress concentrations or stress gradients. This can be checked via FEA.

- The results from monitoring stresses at one location should be able to be related to the structural response at other locations.

- The design of a HMS should factor in ease of access to the structure, weight limitations, and potential interference with on-board activities.

- Consideration should be given to designing redundancy into the system and the reliability and longevity of the sensors.

For fatigue monitoring, data integrity, volume, retrieval, and sampling frequency are important factors (Molent and Aktepe 2000).

Inevitably, the costs associated with setting-up and maintaining hardware as well as processing and analysing large quantities of data, and the complexity of the system, need to be balanced.

\section{Stress Spectra}

Data processing routines were developed in MATLAB 2015b (MathWorks 2015) to convert and filter the raw strain data to stress. Due to the susceptibility of strain measurements to electrical interference from surrounding equipment, spikes are present in the raw data. Spikes are considered short duration electrical transients in voltage and are not representative of a continuous process such as seaway loading. As such, the data processing routines include the removal of spikes. High frequency noise is attenuated by applying a low-pass Chebyshev filter at $8 \mathrm{~Hz}$, which is greater than the three-node bending vibration frequency of $5 \mathrm{~Hz}$ of the 
hull girder (Magoga, et al. 2017). The stress signal was reduced to cycles using the rainflow counting method proposed by Rychlik (1987).

The stress spectra of the considered strain gauge locations, normalised by the maximum measured stress range, are presented in Figure 4. The stresses measured by strain gauge $\mathrm{A}$ are in the vertical direction and by strain gauges $\mathrm{B}$ and $\mathrm{C}$ in the longitudinal direction. The most severe spectrum occurred at strain gauge $\mathrm{C}$, in the global longitudinal direction of a major load-bearing girder underside of the main deck in the engine room.

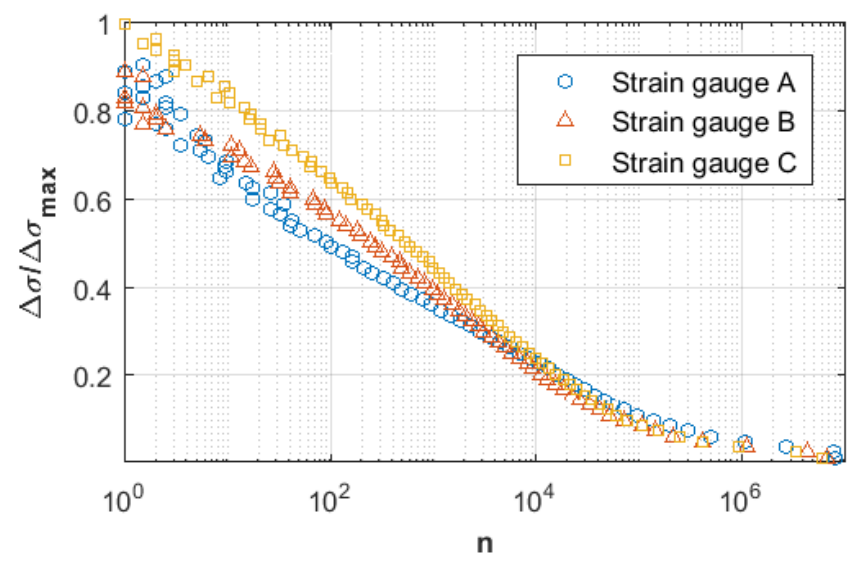

Figure 4. Normalised stress spectra derived from strain measurements. Stress ranges at strain gauge $\mathrm{A}$ are in vertical direction, and at $\mathrm{B}$ and $\mathrm{C}$ in longitudinal direction

\section{Fatigue Life Estimation}

The fatigue life values of the patrol boat details of interest are predicted using the nominal stress approach combined with CDT. It is assumed that the fatigue strength of the examined details is represented by analogous details found in Eurocode 9 (Technical Committee CEN/TC 250 1999).

Eurocode 9 fatigue strength curves are based on estimates of the logarithmic mean and logarithmic standard deviation, assuming a normal distribution, of observed cycles for given stress values. These statistics are used to obtain a characteristic regression line for a 
probability of survival of approximately $97.7 \%$ from the mean, which is less than $80 \%$ of the corresponding mean strength value.

For each detail of interest a reference location (a strain gauge location, with known stress spectra and detail category) was selected. The following criteria are used to select from reference locations from the available strain gauge locations:

- Proximity to the detail, judged as within one frame spacing and at the same height \pm $0.5 \mathrm{~m}$.

- Consistency of the dominant stress direction.

- The detail of interest and the reference location being matched to detail categories from the same table in Eurocode 9.

The fatigue damage was estimated using the stress spectra displayed in Figure 4. To relate the stress spectrum at a reference location to a detail of interest, the spectrum is scaled by the ratio of the stress range at the detail to that of the reference. The stress ratio, $\mathrm{K}$ is calculated using the results of the FEA of the patrol boat under the design crest landing and hollow landing conditions. A limitation of the nominal stress approach in fatigue assessment is that only uni-directional stresses can be incorporated in details provided in Eurocode 9. However, this assumption does not hold true in actual operational conditions. In the proposed method, a three-dimensional (3D) global FEA model of the vessel was developed and the subsequent stress analysis considering design load cases that incorporated global hogging and sagging loads, as well as local slam pressure loading, was considered. This enables stresses in all three directions to be resolved. The dominant stress, usually aligned with the direction of the reference stress, is then used to determine the stress ratio between the reference sensor location and the location of interest. Thus, the effect of this limitation is somewhat reduced. In addition, the interpretation of the stress directions incurred in the structure, with respect to 
the ship heading relative to the principal wave direction, is important. As such, as best as possible, the gauges were adhered to the structure so that the direction of the associated measured stresses were aligned with the estimated dominant stress/load direction. This was verified via $3 \mathrm{D}$ stress analysis.

The selected Eurocode 9 detail categories for the details of interest and reference locations, and the $\mathrm{K}$ factors, are summarised in Table 4.

Table 4. Selected Eurocode 9 detail categories for details of interest and K factors

\begin{tabular}{|c|c|c|c|c|}
\hline & ID-1 & ID-2 & ID-3 & ID-4 \\
\hline $\begin{array}{c}\text { Eurocode } 9 \\
\text { category }\end{array}$ & $\begin{array}{l}\text { 7.4.3 - Welded } \\
\text { one side only, } \\
\text { full penetration } \\
\text { without backing }\end{array}$ & $\begin{array}{c}7.2 .1-\mathrm{Butt} \\
\text { weld from both } \\
\text { sides, full } \\
\text { penetration }\end{array}$ & $\begin{array}{l}11.3 \text { - Double- } \\
\text { sided cross- } \\
\text { welded built-up } \\
\text { beam }\end{array}$ & $\begin{array}{c}9.1 \text { - Double } \\
\text { fillet weld to } \\
\text { transverse } \\
\text { plating }\end{array}$ \\
\hline $\begin{array}{l}\text { Reference } \\
\text { location }\end{array}$ & Strain gauge A & Strain gauge B & Strain gauge $\mathrm{C}$ & Strain gauge B \\
\hline $\bar{K}$ & 3.0 & 4.9 & 1.6 & 3.2 \\
\hline
\end{tabular}

\section{Fatigue Life Results}

Table 5 presents a comparison between the fatigue damage $\mathrm{D}$ predicted at the details of interest and the reference locations. The largest fatigue damage was incurred at ID-2. Interestingly, its reference location (strain gauge B) incurred the smallest fatigue damage. The smallest fatigue damage at a detail of interest was predicted at ID-3. However, the fatigue damage at its reference location (strain gauge $\mathrm{C}$ ) was the greatest. These results highlight that the structure near a strain gauge that measures relatively large stresses may not be the most fatigue-critical. 


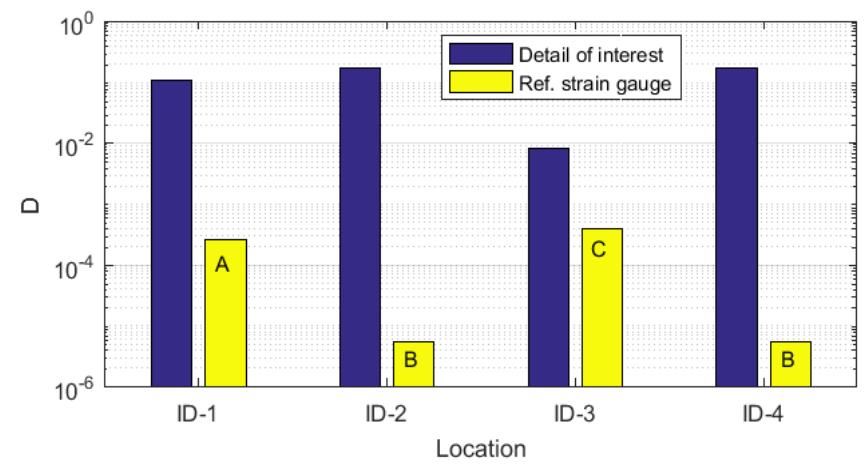

Figure 5. Comparison between fatigue damage at details of interest and respective reference locations

Figure 6 shows the predicted fatigue life, $\mathrm{FL}_{\mathrm{p}}$ of each detail of interest normalised by $\mathrm{FL}_{\mathrm{p}}$ at detail ID-1. The fatigue life was smallest at ID-2, followed by ID-4, ID-1, and ID-3. The values of $\mathrm{FL}_{\mathrm{p}}$ are relatively similar. The exception is $\mathrm{FL}_{\mathrm{p}}$ at ID-3, which is approximately fourteen times greater than $\mathrm{FL}_{\mathrm{p}}$ of ID-1, and fatigue cracking would not expected to occur at this location.

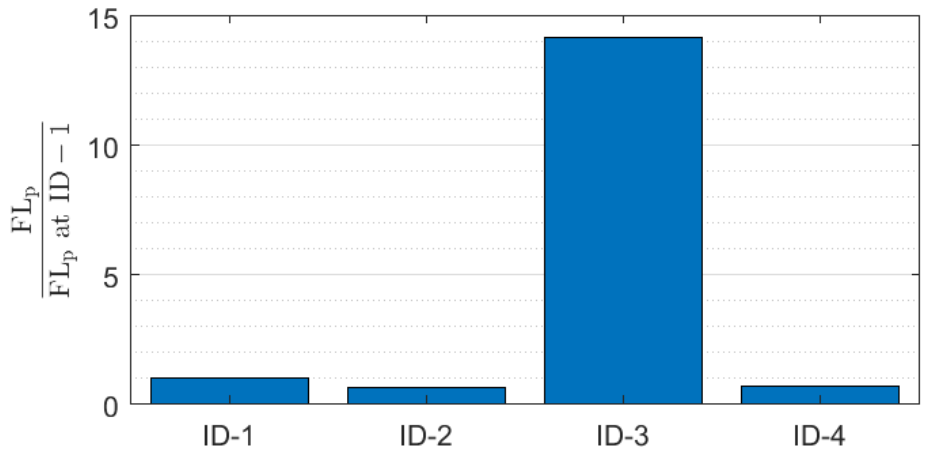

Figure 6. $\mathrm{FL}_{\mathrm{p}}$ of details of interest, normalised by $\mathrm{FL}_{\mathrm{p}}$ of detail ID-1 


\section{Validation}

Both the validity and the significance of the fatigue life predictions can be characterised by the difference between $\mathrm{FL}_{\mathrm{p}}$ and $\mathrm{FL}_{\mathrm{m}}$ as a proportion of the design life $\mathrm{FL}_{\mathrm{d}}$ of the patrol boat. The design life should be the minimum fatigue life of the structure.

Figure 7 indicates that the differences between $\mathrm{FL}_{\mathrm{m}}$ and $\mathrm{FL}_{\mathrm{p}}$ are $8 \%, 7 \%$ and $22 \%$ of $\mathrm{FL}_{\mathrm{d}}$ for details of interest ID-1, ID-2 and ID-4, respectively. The predicted fatigue life at location ID-3 is greater than the design life, and no defects have been reported at this location. There is also agreement between the order of the $\mathrm{FL}_{\mathrm{p}}$ values (shown in Figure 6) and the order of the $\mathrm{FL}_{\mathrm{m}}$ values (given in Table 3) by detail. Thus, the fatigue life predictions are considered to be valid.

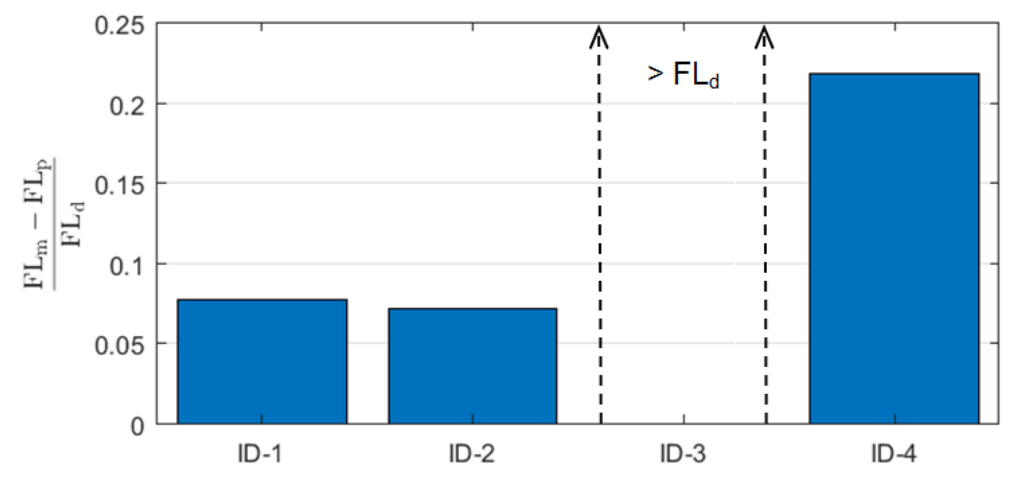

Figure 7. Difference between fatigue life values based on derived stress spectra and maintenance records as ratio of design fatigue life of patrol boat

\section{Feedback to Platform Management}

Options to achieve the desired service life of a ship include service restriction, repair design of joints to have better fatigue resistance, and improved weld dressing (Maddox 2003). The effect of implementing these options on the service life can be quantified after modification of the FEA model and re-selection of the S-N curve as necessary. This is demonstrated in Figure 8, which shows the percentage change in $\mathrm{FL}_{\mathrm{p}}$ of detail of interest ID-1 with changing 
$\mathrm{K}$ applied to the reference stress spectra. For example, a $10 \%$ decrease of $\mathrm{K}$ results in a $50 \%$ increase in the fatigue life. Conversely, if a nearby structural item fails and there is load shedding to the joint, the stresses would be expected to be greater. For instance, a $10 \%$ increase of $\mathrm{K}$ leads to a fatigue life penalty of $30 \%$.

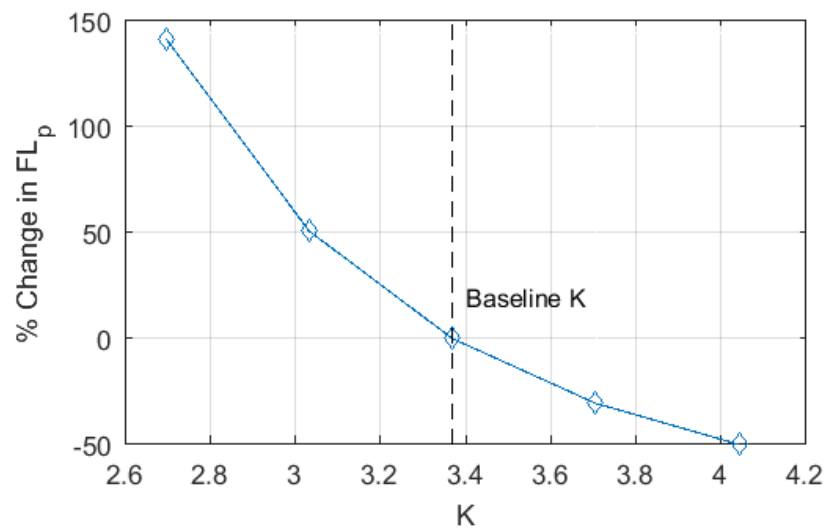

Figure 8. Change in $\mathrm{FL}_{\mathrm{p}}$ with change in $\mathrm{K}$ applied to reference stress spectra at detail of interest ID-1

\section{Discussion}

Issues with the structural performance of the patrol boat are not unexpected due to its weightoptimised structure and the requirement to operate in harsh sea conditions when a commercial vessel would otherwise seek shelter. The United States Navy also reviewed hull girder, slamming and vehicle deck design loads for the Littoral Combat Ship because of hull cracking (Kramer, Haugan and Fredriksen 2006). Even in conventional steel ships, cracks can initiate and propagate before the required service life (Ma and Bea 1995, Soliman, et al. 2015). However, feedback from operations provides knowledge on fatigue-critical details typical of HSLC.

The approach taken to translate a reference stress spectrum to a detail of interest is to use a single scaling factor. This approach is applicable when the strain gauge is located 
sufficiently close to the detail of interest, as it can be assumed that the response at the detail of interest is directly proportional to that at the strain gauge location. However, this assumption may not hold when the strain gauge is far from the detail of interest. In this case, a more complex transfer function should be formulated (Molent 1998, Swanton and Walker 1997).

The effects of weld repairs are not explored explicitly in this paper. That is, $\mathrm{FL}_{\mathrm{m}}$ is treated as the 'first' fatigue life of the details of interest. However, as the proposed throughlife hybrid fatigue assessment method is a feedback loop it can be used to predict the time between completion of a repair to re-cracking, and to assess different repair solutions.

In resource-limited environments, there is a trade-off between the required accuracy and the cost of through-life fatigue management of an in-service, complex structure. Recently, research has been conducted to determine cost-efficient HMS plans that provide crucial information regarding ship performance and optimum maintenance schedules (Koboević, Bebić and Kurtela 2018, Sabatino and Frangopol 2017). In the offshore industry, codes exist to manage structural integrity, such as ISO 19902:2007 (International Organization for Standardization 2014) and DNV GL's Offshore Standards (DNV GL 2017). These codes require an evaluation of the resistance against fatigue damage and, based on the results, establishment of inspection programmes both during construction and in-service. Such programmes are considered conservative and expensive, and ways to improve their efficiency are being researched (Aeran, Siriwardane, Mikkelsen and Langen 2017, Mohammadi, Galgoul, Starossek and Videiro 2016). Fatigue analysis of an in-service, complex structure is very often a balance between practical considerations including the availability of data, time and resource limitations, and the required accuracy. A trade-off study between the required accuracy and cost of through-life fatigue management is part of future research. In addition, to better manage uncertainties reliability-based fatigue 
assessment is worthy of future investigation (Collette and Incecik 2006, Lotsberg,

Sigurdsson, Fjeldstad and Moan 2016, Soliman, et al. 2015).

\section{Conclusion}

A method to measure and monitor full-scale structural responses and the operational profile, combined with the maintenance history, to evaluate the fatigue life evaluation of a naval vessel is proposed. Four different aluminium welded details were studied. The fatigue damage was estimated by employing cumulative damage theory, combined with Eurocode 9 $\mathrm{S}-\mathrm{N}$ curves, to stress spectra derived from in-service strain measurements. A stress spectrum was related to a detail by applying the ratio of the maximum stress ranges of the detail to the strain gauge location. The resulting fatigue life predictions correlate well to fleet maintenance data. The proposed method is efficient because it is properly linked to stress analysis, and is a trade-off between accuracy and effort. The present study can be extended by employing a probabilistic approach to take into account the parameters of influence in fatigue assessment. 


\section{References}

56.8m Armidale Class Patrol Boat Drawings. 2003. Henderson, Australia: Austal Ships.

Aeran A, Siriwardane SC, Mikkelsen O, Langen I. 2017. A framework to assess structural integrity of ageing offshore jacket structures for life extension. Marine Structures.56:237259.

Chakarov K, Garbatov Y, Guedes Soares C. 2008. Hot spot stress and stress concentration factors due to different fabrication imperfections in deck structures. International Shipbuilding Progress.55:47-62.

Collette M, Incecik A. 2006. An approach for reliability-based fatigue design of welded joints on aluminium high-speed vessels. Journal of Ship Research.50:85-98.

Common Structural Rules for Bulk Carriers and Oil Tankers. 2010. London, United Kingdom.

Cosso GL, Rizzo CM, Servetto C. 2016. Fitness-for-service assessment of defected welded structural details by experimental evaluation of the fatigue resistance S-N curve. Welding in the World.60:847-858.

Cui W, Wang F, Huang X. 2011. A unified fatigue life prediction method for marine structures. Marine Structures.24:153-181.

Det Norske Veritas. 2011. Rules for Classification of High Speed, Light Craft and Naval Surface Craft. Høvik, Norway.

Airworthiness Design Requirements Manual Canberra: Australian Defence Force Available from

http://www.defence.gov.au/DGTA/Documents/Publications/7001054/eADRM\%20web/7117. htm

DNV GL. 2017. Offshore Standards. Oslo, Norway. (DNVGL-OS). 
Doshi K, Vhanmane S. 2013. Probabilistic fracture mechanics based fatigue evaluation of ship structural details. Ocean Engineering.61:26-38.

DRS Defense Solutions. 2013. MAESTRO 11.0.0. Stevensville.

Drummen I, Hageman R, Stambaugh K. 2017. Structural fatigue life assessment and maintenance needs for a new class of US Coast Guard Cutters. In: Life-Cycle of Engineering Systems: Emphasis on Sustainable Civil Infrastructure. p. 1919-1926.

Du J, Li H, Zhang M, Wang S. 2015. A novel hybrid frequency-time domain method for the fatigue damage assessment of offshore structures. Ocean Engineering.98:57-65.

Ferraris S, Farinetti V. 2008. The problem of fatigue on large high-speed craft and the comparison between the behavior of high tensile steel and aluminum alloy structures: The view of an international shipbuilder. Journal of Ship Production.24:116-123.

Groden M, Collette M. 2017. Fusing fleet in-service measurements using Bayesian networks. Marine Structures.54:38-49.

Hess P, Aksu S, Blake JIR, Boote D, Caridis P, Egorov A, Fjeldstad A, Hoogeland M, Murayama H, Anderson MR, et al. 2015. Structural Longevity. In: Proceedings of the 19th International Ship and Offshore Structures Congress. Cascais, Portugal. p. 211-287.

Hifi N, Barltrop N. 2015. Correction of prediction model output for structural design and risk-based inspection and maintenance planning. Ocean Engineering.97:114-125.

Hobbacher A. 2008. Recommendations for fatigue design of welded joints and components. Paris, France: International Institute of Welding. (XIII-1539-96 / XV-845-96).

Hodapp D, Collette M, Troesch A. 2013. Nonlinear Fatigue Crack Growth Preidctions for Simple Specimens Subject to Time-Dependant Ship Structural Loading Sequences Trans Soc Naval Archit Marine Eng.121. 
Hodkiewicz M, Tien-Wei Ho M. 2016. Cleaning historical maintenance work order data for reliability analysis. Journal of Quality in Maintenance Engineering.22:146-163.

Huang TD, Harbison M, Kvidahl L, Niolet D, Walks J, Christein JP, Smitherman M, Phillippi M, Dong P, De Can L, et al. 2016. Reduction of overwelding and distortion for naval surface combatants. Part 2: Weld sizing effects on shear and fatigue performance. Journal of Ship Production and Design.32:21-36.

Hwang MR, Lee TK, Kang DH, Suh YS. 2016. A study on ice-induced fatigue life estimation based on measured data of the ARAON. Conference Paper presented at: International Offshore and Polar Engineering Conference.

Ibrahim RA. 2015. Overview of structural life assessment and reliability, part II: Fatigue life and reliability assessment of naval ship structures. Journal of Ship Production and Design.31:100-128.

International Organization for Standardization. 2014. Petroleum and natural gas industries fixed steel offshore structures. (ISO 19902:2007 + Amd 1:2013).

Johnson NR, Lynch JP, Collette MD. 2018. Response and fatigue assessment of high speed aluminium hulls using short-term wireless hull monitoring. Structure and Infrastructure Engineering. 14:634-651.

Koboević Ž, Bebić D, Kurtela Ž. 2018. New approach to monitoring hull condition of ships as objective for selecting optimal docking period. Ships and Offshore Structures.1-9.

Koenig P, Nalchajian D, Hootman J. 2009. Ship Service Life and Naval Force Structure. Naval Engineers Journal.121:69-77.

Kramer R, Haugan G, Fredriksen A. 2006. US navy high speed craft - Comparison of ABS and DNV structural requirements. Transactions - Society of Naval Architects and Marine Engineers.113:340-366. 
Kramer R, Rampolla B, Magnussen A. 2000. Fatigue of Aluminum Structural Weldments. Washington, United States: Ship Structure Committee. (SSC-410).

Lotsberg I, Sigurdsson G, Fjeldstad A, Moan T. 2016. Probabilistic methods for planning of inspection for fatigue cracks in offshore structures. Marine Structures.46:167-192.

Ma K, Bea R. 1995. A Repair Management System for Fatigue Cracks in Ships. SNAME Transactions.103:343 - 396.

Maddox SJ. 2003. Review of fatigue assessment procedures for welded aluminium structures. International Journal of Fatigue.25:1359-1378.

Magoga T, Aksu S, Cannon S, Ojeda R, Thomas G. 2017. Identification of Slam Events Experienced by a High-Speed Craft. Ocean Engineering.140:309-321.

Magoga T, Dwyer D. 2018. Fatigue Life as a Variable in Assessing Naval Ship Flexibility. Naval Engineers Journal.130.

MathWorks. 2015. MATLAB R2015b Natick, United States of America.

Matic T, Domazet Z. 2005. Determination of structural stress for fatigue analysis of welded aluminium components subjected to bending. Fatigue \& Fracture of Engineering Materials \& Structures.28:835-844.

Meneghetti G. 2008. The peak stress method applied to fatigue assessments of steel and aluminium fillet-welded joints subjected to mode I loading. Fatigue and Fracture of Engineering Materials and Structures.31:346-369.

Structural Integrity Handbook Bristol, United Kingdom: Ministry of Defence. Available from

https://www.gov.uk/government/uploads/system/uploads/attachment_data/file/426205/Struct ural_Integrity_Handbook.pdf

Miner M. 1945. Cumulative damage in fatigue. Journal of Applied Mechanics.12:159-164. 
Mohammadi SF, Galgoul NS, Starossek U, Videiro PM. 2016. An efficient time domain fatigue analysis and its comparison to spectral fatigue assessment for an offshore jacket structure. Marine Structures.49:97-115.

Molent L. 1998. A unified approach to fatigue usage monitoring of fighter aircraft based on F/A-18 experience. ICAS98, International Council of the Aeronautical Sciences.

Molent L, Aktepe B. 2000. Review of fatigue monitoring of agile military aircraft. Fatigue \& Fracture of Engineering Materials \& Structures.23:767-785.

Neuberg O, Drimer N. 2017. Fatigue limit state design of fast boats. Marine Structures.55:1736.

Okasha NM, Frangopol DM, Saydam D, Salvino LW. 2011. Reliability analysis and damage detection in high-speed naval craft based on structural health monitoring data. Structural Health Monitoring.10:361-379.

Phelps B, Morris B. 2013. Review of Hull Structural Monitoring Systems for Navy Ships. Melbourne, Australia: Defence Science and Technology Organisation. (DSTO-TR-2818).

Ravi Chandran KS, Chang P, Cashman GT. 2010. Competing failure modes and complex S$\mathrm{N}$ curves in fatigue of structural materials. International Journal of Fatigue. 32:482-491.

Rules for Classification of High Speed, Light Craft and Naval Surface Craft. 1996. Høvik, Norway.

Rychlik I. 1987. A new definition of the rainflow cycle counting method. International Journal of Fatigue.9:119-121.

Sabatino S, Frangopol DM. 2017. Decision making framework for optimal SHM planning of ship structures considering availability and utility. Ocean Engineering.135:194-206. 
Shen W, Yan R, Barltrop N, Liu E, Song L. 2016. A method of determining structural stress for fatigue strength evaluation of welded joints based on notch stress strength theory. International Journal of Fatigue.90:87-98.

Sielski R. 2008. Research Needs in Aluminum Structures. Ships and Offshore Structures.3:57-65.

Soliman M, Barone G, Frangopol DM. 2015. Fatigue reliability and service life prediction of aluminum naval ship details based on monitoring data. Structural Health Monitoring.14:3-19.

Stambaugh K, Drummen I, Cleary C, Sheinberg R, Kaminski M. 2014. Structural fatigue life assessment and sustainment implications for a new class of US coast guard cutters. Transactions - Society of Naval Architects and Marine Engineers. 122:434-444.

Swanton G, Walker K. 1997. Development of a Transfer function to Relate F-111 Aircraft Fatigue Data Analysis System (AFDAS) Strain Outputs to Loads and Control Point Stresses. Melbourne, Australia: Defence Science and Technology Organisation. (DSTO-TR-0563).

Swartz RA, Zimmerman AT, Lynch JP, Rosario J, Brady T, Salvino L, Law KH. 2012. Hybrid wireless hull monitoring system for naval combat vessels. Structure and Infrastructure Engineering.8:621-638.

Technical Committee CEN/TC 250. 1999. Eurocode 9: Design of aluminium structures. Brussels: B Standards.

Temple D, Collette M. 2015. Minimizing lifetime structural costs: Optimizing for production and maintenance under service life uncertainty. Marine Structures.40:60-72.

Thévenet D, Ghanameh MF, Zeghloul A. 2013. Fatigue strength assessment of tubular welded joints by an alternative structural stress approach. International Journal of Fatigue.51:74-82.

Vincent P, Gardiner C, Wilson A, Ellery D, Armstrong T. 2008. Installation of a sensor network on an RAN Armidale Class Patrol Boat. Materials Forum.33:307-316. 
Xiao Z-G, Yamada K. 2004. A method of determining geometric stress for fatigue strength evaluation of steel welded joints. International Journal of Fatigue.26:1277-1293.

Yeter B, Garbatov Y, Guedes Soares C. 2016. Evaluation of fatigue damage model predictions for fixed offshore wind turbine support structures. International Journal of Fatigue.87:71-80.

Zhang Y-H, Maddox SJ. 2009. Investigation of fatigue damage to welded joints under variable amplitude loading spectra. International Journal of Fatigue.31:138-152.

Zhu J, Collette M. 2011. Lifecycle Fatigue Management for High-Speed Vessels Using Local Approaches. 11th International Conference on Fast Sea Transportation. 